\title{
Pest species diversity enhances control of spider mites and whiteflies by a generalist phytoseiid predator
}

\author{
Gerben J. Messelink • Roos Van Maanen • \\ Renata Van Holstein-Saj • Maurice W. Sabelis • \\ Arne Janssen
}

Received: 31 August 2009/Accepted: 23 November 2009/Published online: 1 December 2009

(C) The Author(s) 2009. This article is published with open access at Springerlink.com

\begin{abstract}
To test the hypothesis that pest species diversity enhances biological pest control with generalist predators, we studied the dynamics of three major pest species on greenhouse cucumber: Western flower thrips, Frankliniella occidentalis (Pergande), greenhouse whitefly, Trialeurodes vaporariorum (Westwood), and two-spotted spider mites, Tetranychus urticae Koch in combination with the predator species Amblyseius swirskii Athias-Henriot. When spider mites infested plants prior to predator release, predatory mites were not capable of controlling spider mite populations in the absence of other pest species. A laboratory experiment showed that predators were hindered by the webbing of spider mites. In a greenhouse experiment, spider mite leaf damage was lower in the presence of thrips and predators than in the presence of whiteflies and predators, but damage was lowest in the presence of thrips, whiteflies and
\end{abstract}

Handling Editor: Patrick De Clercq.

G. J. Messelink $(\bowtie) \cdot$ R. Van Holstein-Saj

Wageningen UR Greenhouse Horticulture,

PO Box 20, 2265 ZG Bleiswijk, The Netherlands

e-mail: Gerben.Messelink@wur.nl

R. Van Maanen - M. W. Sabelis · A. Janssen

IBED, Section Population Biology, University

of Amsterdam, Science Park 904, 1098 XH Amsterdam,

The Netherlands predators. Whitefly control was also improved in the presence of thrips. The lower levels of spider mite leaf damage probably resulted from (1) a strong numerical response of the predator (up to 50 times higher densities) when a second and third pest species were present in addition to spider mites, and (2) from $A$. swirskii attacking mobile spider mite stages outside or near the edges of the spider mite webbing. Interactions of spider mites with thrips and whiteflies might also result in suppression of spider mites. However, when predators were released prior to spider mite infestations in the absence of other pest species, but with pollen as food for the predators, we found increased suppression of spider mites with increased numbers of predators released, confirming the role of predators in spider mite control. Thus, our study provides evidence that diversity of pest species can enhance biological control through increased predator densities.

Keywords Biological control - Tetranychus urticae · Frankliniella occidentalis $\cdot$ Trialeurodes vaporariorum - Amblyseius swirskii · Biodiversity · Food web interactions $\cdot$ Pest interactions

\section{Introduction}

Much research has been devoted as to whether the presence of multiple natural enemies leads to more efficient pest suppression than the presence of single enemy species (Rosenheim et al. 1995; Denoth et al. 
2002; Cardinale et al. 2003; Casula et al. 2006). Empirical studies show that increasing diversity of natural enemies can result in a full spectrum of outcomes, including additive, antagonistic, synergistic, or no effects on biological control (Casula et al. 2006; Janssen et al. 2006, 2007). Less attention has been paid to the impact of pest species diversity on biological control. Most pest management programs in modern greenhouse cropping systems are focused on excluding and eliminating pest species as much as possible, resulting in low pest species diversity. However, indirect interactions occurring among various pest species may enhance biological control (Janssen et al. 1998; Harmon and Andow 2004; Prasad and Snyder 2006; Van Veen et al. 2006).

Such an indirect interaction occurs when the density of one prey species affects the density of a polyphagous natural enemy, which consequently affects the density of a second prey species. Holt (1977) was the first to develop theory on this mode of indirect interaction. He showed that the equilibrium density of a population of one prey species decreases when that of another, non-competing prey species is increased. Holt coined the term "apparent competition" because it appears as if the two species compete for a shared resource, whereas in fact the two prey populations interact via the shared predator. Subsequently, theory was developed for the case of shortterm dynamics of systems involving multiple prey that share the same natural enemy (Holt and Kotler 1987; Abrams and Matsuda 1996; Abrams et al. 1998). Such short-term, non-equilibrium dynamics are a more realistic scenario in agricultural systems with a short production cycle than the equilibrium dynamics studied by Holt (1977) and Holt and Lawton (1994). The theory on short-term dynamics shows that predators can not only mediate apparent competition between two of their prey species, but also apparent mutualism. In the latter case, predator satiation results in a short-term positive indirect interaction between its prey species. With respect to biological control, some studies have indeed demonstrated that the control of a pest species can be improved by the presence of another pest species (Collyer 1964; Karban et al. 1994; Liu et al. 2006; Messelink et al. 2008), whereas disruption of biological control through predator satiation in the shortterm has also been demonstrated (Koss and Snyder 2005; Symondson et al. 2006).
So far, both theory and experiments on the effects of a shared predator have ignored the effects of a mixed diet on predator populations. Different prey can have complementary nutritional values (Wallin et al. 1992; Toft 1995; Evans et al. 1999), and this can amplify the effects of predator-mediated apparent competition. Hence, the presence of several prey species can increase predator populations through the increased availability of food as well as through the higher quality of a mixed diet. Based on these mechanisms, pest species diversity in combination with predators attacking various prey species can enhance biological control (Messelink et al. 2008).

This study was designed to further evaluate the hypothesis that increasing pest species diversity can enhance biological control with generalist predators. We studied the dynamics of three major pest species in greenhouse crops, i.e. Western flower thrips, Frankliniella occidentalis (Pergande), greenhouse whiteflies, Trialeurodes vaporariorum (Westwood), two-spotted spider mites, Tetranychus urticae Koch and the predator Amblyseius swirskii Athias-Henriot (Zannou et al. 2007). The predatory mite A. swirskii has proven to be an effective control agent for thrips (Messelink et al. 2006) and whiteflies (Nomikou et al. 2001, 2002), whereas its effect on spider mites is still unclear. Moreover, control of whiteflies is improved when thrips are present in low densities (Messelink et al. 2008). Although A. swirskii does feed on spider mites (Momen and El-Saway 1993), greenhouse observations suggest that the webbing produced by spider mites impedes effective control because A. swirskii is not able to enter it (Messelink, personal observations). It has been suggested that one of the functions of spider mite webbing is defence against predators, and the way in which predatory mites cope with this webbing is suggested to depend on the dorsal chaetotaxy of the predators (Sabelis and Bakker 1992). The predator A. swirskii has short dorsal setae, and is therefore expected to be hindered by spider mite webbing. We first verified this by measuring predation rates of spider mite eggs by A. swirskii in the presence and absence of spider mite webbing. Subsequently, we verified that $A$. swirskii is not capable of controlling spider mite populations in the absence of other pest species. Finally, we investigated whether spider mite control by A. swirskii can be enhanced by the presence of the other pest species, i.e. thrips and whiteflies. A further experiment 
was done to shed some light on the possible mechanisms responsible for increased spider mite control in the presence of other pests. It is not our aim here to completely disentangle how multiple pest species interact, i.e. directly, indirectly via the plant, indirectly via the shared predator or via any combination of these mechanisms. Our primary goal is to establish the extent to which multiple pest species affect control efficacy and discuss the interactions mentioned.

\section{Materials and methods}

\section{Cultures}

The predatory mite A. swirskii was reared on a diet of cattail pollen (Typha latifolia L.) in climate rooms, under $16 \mathrm{~h}$ of artificial illumination per day, at $22^{\circ} \mathrm{C}$ and $70 \% \mathrm{RH}$ on plastic arenas of a type described by Overmeer (1985). For the experiment with predator densities, A. swirskii was obtained from Koppert Biological Systems (Berkel en Rodenrijs, The Netherlands). These mites were reared on bran containing the sugar mite Carpoglyphus lactis L. All prey/pest species were reared on plants in greenhouse compartments. Two-spotted spider mites were reared on bean plants, Phaseolus vulgaris L., Western flower thrips were reared on flowering chrysanthemum plants (Dendranthema grandiflora Tzvelev, cv. Miramar) and the greenhouse whitefly was reared on tobacco plants (Nicotiana tabacum L.). For assessing the effects of spider mite webbing on predatory mites in the laboratory, we reared the predatory mite species Phytoseiulus persimilis Athias-Henriot and Neoseiulus californicus (McGregor) on spider miteinfested cucumber plants in greenhouses.

\section{Effect of webbing on predation}

A laboratory experiment was set up to assess the extent to which spider mite webbing hinders predation by A. swirskii. Although spider mite eggs are less suitable for development of A. swirskii than the mobile stages of this prey (van Maanen, personal observations), we used eggs because they do not move from the web where they are deposited. Predation by A. swirskii was compared with that of two other species of predatory mite, $P$. persimilis and
N. californicus, commonly used for control of spider mites. This comparative test served to assess the impact of webbing on predation of spider mite eggs. We placed cucumber leaf discs $(3 \mathrm{~cm}$ diameter, cut from the inter-vein area of four-week-old plants) upside down on water-saturated cotton wool in plastic boxes $(14 \times 20 \mathrm{~cm})$, six leaf discs per box. Three female spider mites were placed on each leaf disc for two days, resulting in a colony with 40 eggs on average. Spider mites were prodded with a small paintbrush to make them move out of the webbing without harming the web structure, and the eggs were counted. The webbing was removed from half of the leaf discs with a fine needle. Single, young adult female predators (1-6 days old since their last moult, starved for one day), were placed on the leaf discs and the boxes with discs were incubated in a climate room $\left(25^{\circ} \mathrm{C}\right.$ and $\left.16 / 8 \mathrm{~L} / \mathrm{D}\right)$. The surviving eggs were counted after $24 \mathrm{~h}$. Treatments were replicated 12 times with new predator individuals. Differences between treatments involving web or web removal and treatments involving different predator species were analysed using an ANOVA on the log-transformed numbers of eggs, followed by Fisher's LSD (Least Significant Difference) test at the 5\% confidence level.

Spider mite control by A. swirskii

We studied the population dynamics of spider mites and A. swirskii in the absence of other pest species on cucumber plants (cv. Aviance, powdery mildew resistant) in two separate greenhouse compartments $\left(18 \mathrm{~m}^{2}\right)$. So there was only one treatment, in which the spider mites were released prior to the predatory mites. Each compartment contained two tables $(1 \times 3 \mathrm{~m})$ on which plants were grown up to a $1.5 \mathrm{~m}$ high wire to support the crop. Plants were grown in rock wool blocks. Side-shoots were removed until the top of the plant reached the crop supporting wire, and all further plant shoots were suspended from the wire. Each greenhouse compartment had a small entrance corridor, and was ventilated with an air pressure system in order to minimize contamination by organisms from outside. The plants had six leaves when the experiment started in March 2006. Roots were preventively treated against Pythium spp. by soaking the rock wool blocks in a $0.1 \%$ solution of propamocarb (Previcur $\mathrm{N}^{\circledR}$, Bayer Crop 
Science). No further pesticides were used. Four plants were placed on two pieces of rock wool substrate on each table. The rock wool mats were continuously immersed in a nutrient solution that was automatically supplied twice a day. One day after planting, the plants were infested with spider mites by adding two cucumber leaf discs ( $2 \mathrm{~cm}$ diameter), each containing ten females that were collected from the culture. These leaf discs were put on the fourth and fifth leaf of each plant, counted from the lowest leaf. Predatory mites were released seven days after introducing the spider mites. Female predatory mites were collected in the laboratory with a fine paintbrush and placed on leaf discs of sweet pepper (Capsicum annuиm L.) (2-cm-diameter) containing cattail pollen. One leaf disc with 15 mites was introduced onto each cucumber plant on the 7th leaf from below. Each table was considered as a single replicate. Hence, there were four replicates.

The experiment lasted 11 weeks, roughly corresponding to the standard cropping period for modern glasshouse cultures. Cucumbers were harvested as soon as they reached the standard fruit size, but fruit yield was not measured. The numbers of predatory mites and the percentage of leaf surface with spider mite damage were assessed 5, 7, 9 and 11 weeks after introducing the pest species. Assessment of the populations was done on six leaves of each replicate. The leaves were collected by randomly choosing three shoots of which the sixth and eighth leaf, counted from the tip, were collected. Each leaf was put in a separate plastic bag and transported to the laboratory, where it was cut into strips of $5 \mathrm{~cm}$ wide. The predatory mites were counted on both sides of the leaves using a stereomicroscope $(40 \times)$. Spider mite damage was assessed by estimating the percentage of leaf damage by persons which were trained for these observations with the computer program "Distrain" (Tomerlin and Howell 1988).

\section{Effects of prey diversity on pest control}

The combined control of whiteflies, thrips and spider mites by $A$. swirskii was studied on plants in greenhouse compartments as explained above and with various combinations of pests: (1) spider mites plus thrips, (2) spider mites plus whiteflies, (3) spider mites plus thrips and whiteflies, (4) thrips only. Combinations of whitefly and thrips were examined in an earlier experiment, described elsewhere (Messelink et al. 2008). Experiments were carried out in eight compartments simultaneous with the experiment on spider mite control. Each treatment was replicated four times.

For all treatments with thrips, female thrips were collected with an aspirator from a culture on chrysanthemum and introduced at a rate of ten per plant. For all treatments with whiteflies, adult greenhouse whitefly (sex ratio 1:1.27 male:female) were collected with an aspirator from a culture on tobacco plants and released at a rate of 40 per plant. All pest species except spider mites were released one day after planting. Predatory mites ( 15 females per plant) were released seven days after introducing the pests, at the start of the second week (thus, exactly at the same time and same number as in the experiment on spider mite control). Spider mites were introduced three weeks later than the predatory mites, in order to evaluate the effects of an already established predator population. A period of three weeks was chosen to allow the predator populations to increase on the food present in the crop (thrips, whiteflies or both). Labelled cucumber leaves of young side shoots were provided with small cucumber leaf discs ( $2 \mathrm{~cm}$ diameter), each containing 20 female spider mites collected from the culture on bean plants. These discs with spider mite colonies were applied to four leaves per replicate. During the next six weeks, we assessed the percentage of spider mite damage on four younger and four older leaves, next to the leaves on which the spider mites were released. Assessments per leaf were done as described in the experiment on spider mite control by the same trained person, as it was impossible to count mites on so many plants using a non-destructive method. The typical leaf tissue damage caused by spider mites (Park and Lee 2002) could easily be distinguished from thrips damage. Heavily infested and desiccating/wilting leaves were considered as $100 \%$ damaged by spider mites. A control treatment with spider mites added to plants with only predatory mites could not be included, because predatory mites do not survive on plants in a period of three weeks without any prey. The numbers of predatory mites, thrips and whiteflies were assessed 5, 7, 9 and 11 weeks after starting the experiment (and introducing the pest species). Assessment of the populations was done on six leaves in each treatment, as described above. The number of predatory mites, thrips and whiteflies were counted on both sides of the 
strips of leaf using a stereomicroscope $(40 \times)$. Predatory mites were regularly slide-mounted for identification to species with the aid of a phase contrast microscope $(400 \times)$. Only the juvenile stages of thrips and whiteflies were counted because adults fly away when leaves are collected. When the densities of whiteflies exceeded 500 individuals per leaf, densities were assessed only on representative parts of the underside of each leaf, and then extrapolated to the whole surface of the leaf. The average temperature and relative humidity were comparable among greenhouse compartments $\left(22^{\circ} \mathrm{C}\right.$ and $\left.74 \% \mathrm{RH}\right)$.

For statistical analyses, a repeated measures ANOVA was performed on the arcsine square-root transformed fractions of estimated leaf damage by spider mites. The time since introduction of the pest organisms was chosen as the repeated measure variable. The same repeated measures analyses were performed for densities of thrips, whiteflies and predators after a $\log (x+1)$ transformation. Differences between treatments were tested at a $5 \%$ confidence level using Fisher's LSD method.

\section{Effects of predator density on spider mite control}

A third greenhouse experiment was carried out to test the effects of densities of A. swirskii on the establishment and population dynamics of spider mites in a situation where the predators were introduced one week prior to spider mite infestation. Differences in spider mite densities among treatments in the former experiment might not only be caused by predator densities, but also by interactions of thrips and whiteflies with spider mites, such as resource competition, induced plant resistance or predation by thrips. We therefore released predators in two densities prior to spider mite infestations in the absence of the other two pest species. In this way, the effects of thrips and whitefly presence on spider mite densities through the shared predator population was mimicked, while excluding the other interactions between spider mites and the other pests. In one greenhouse compartment of $24 \mathrm{~m}^{2}$, we placed eight cucumber plants (cv. Filia, powdery mildew resistant) on rockwool mats on each of three tables $(1.5 \times 3 \mathrm{~m})$. These plants were treated once with Abamectine when they were two weeks old, to keep them free of thrips. Plants were grown as in the experiments described above. Each plant was isolated and did not touch other plants and was allowed to grow up to a $2 \mathrm{~m}$ high wire that supported the plant. When the plants were four weeks old, with 7-8 full-grown leaves, we divided the plants into three groups, and treated them with (1) no predatory mites (control), (2) a low density of 50 predatory mites per plant and (3) a high density of 500 predatory mites per plant. The predatory mites were released as a mixture with bran and the sugar mite C. lactis (Koppert Biological Systems, Berkel en Rodenrijs, The Netherlands), and they were deposited on top of the rockwool blocks near the base of the plants, from where the mites were able to walk up the plants. The few sugar mites present were not observed to walk onto the plants. We released the predators one week prior to the spider mite infestations to allow them to colonize the plant. Because the plants were devoid of prey, and predatory mites do not survive on plants without food, we added $20 \mu \mathrm{g}$ of pollen of T. latifolia as food for the predators onto all plants on the 7th leaf from below. Plants with the same treatment were placed on one table to avoid contamination among treatments. The dispersal of mites among plants was impeded by placing sticky plates around the rockwool slabs on which the plants were standing. Each plant was considered as one replicate. One week after the predator releases, all plants were infested with spider mites on the 9th leaf (counted from below) by adding one cucumber leaf disc $(2 \mathrm{~cm}$ diameter), each containing 20 females, collected from a culture on bean plants. The numbers of spider mites and predatory mites were assessed on these leaves two weeks later by cutting them and counting the mites using a stereo microscope $(40 \times)$ as described in the greenhouse experiments above. The average greenhouse temperature was $22^{\circ} \mathrm{C}$ and the average relative humidity $74 \%$. Effects of treatments on spider mite densities were analysed using an ANOVA on the $\log (x+1)$-transformed numbers of the sum of eggs and mobile stages. Differences between treatments were tested at a 5\% confidence level using Fisher's LSD method.

\section{Results}

Effect of webbing on predation

Spider mite webbing had a significant effect on the predation of spider mite eggs by $A$. swirskii $\left(F_{5,64}=20.68, P<0.001\right)$, predation was reduced 
by $57 \%$ (Fig. 1). The presence of webbing had no impact on predation by the predatory mites $P$. persimilis and $N$. californicus. In the absence of webbing, the predation rate of $A$. swirskii was also lower than that of $P$. persimilis (Fig. 1). The maximum predation rate of $P$. persimilis might even be higher than observed here because spider mite eggs were almost depleted in some replicates. In the $N$. californicus and A. swirskii treatment, ample amounts of eggs were available throughout the experiment.

Spider mite control by $A$. swirskii

Amblyseius swirskii was not able to control spider mites on cucumber plants without populations of other pest species (Fig. 2). At the end of the experiment, the plants were completely covered by spider mite webbing. Crop growth was poor and there were many desiccated leaves. Though A. swirskii was able to establish, densities remained low $\left(<1.3\right.$ leaf $\left.^{-1}\right)$, at least until week 9 (Fig. 2). At the end of the experiment, a light contamination with thrips was observed in all replicates (average 0.2 and 0.3 larvae leaf $^{-1}$ in respectively week 9 and 11), which may explain the increase in predator densities (Fig. 2).

\section{Effects of prey diversity on pest control}

When spider mites were released on plants with thrips, whiteflies or thrips plus whiteflies, there was a strong effect of pest treatment on leaf damage by spider mites (Fig. 3), resulting in significant

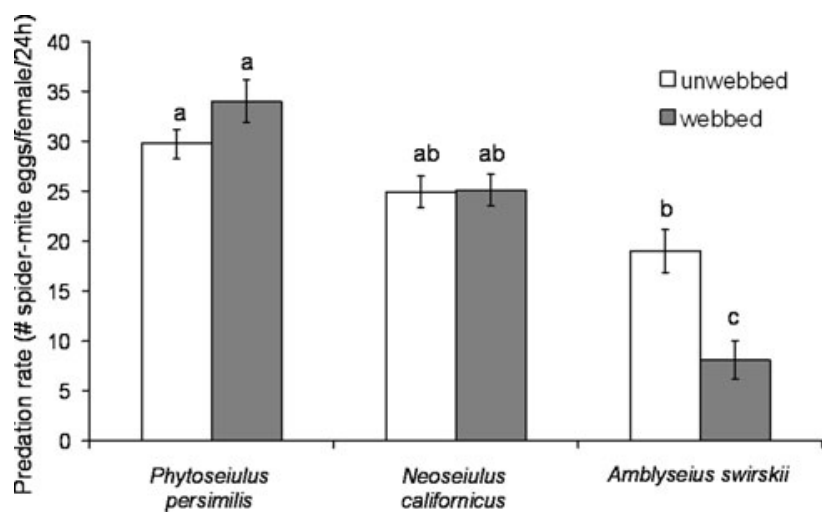

Fig. 1 Predation rates of three predatory mite species on twospotted spider mite eggs on cucumber leaf discs with (grey bars) or without (white bars) spider mite webbing. Shown are average numbers of spider mite eggs consumed $( \pm \mathrm{SE})$ per

female predatory mite in $24 \mathrm{~h}$. Different letters indicate significant differences among treatments (Fisher's LSD test, $P<0.05)$

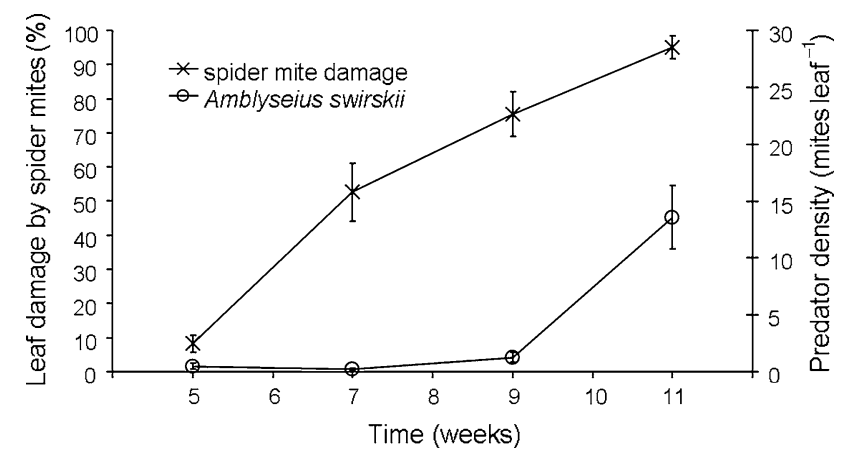

Fig. 2 The dynamics of two-spotted spider mite damage and of numbers of predatory mites (A. swirskii) during an 11 week greenhouse experiment. Spider mites were added at the start of the experiment (week 1), predators were added in the second week. No other pest species were released. Shown are average percentages $( \pm \mathrm{SE})$ of leaf damage and average densities ( $\pm \mathrm{SE}$ ) of the predatory mite A. swirskii 
differences among treatments $\left(F_{2,42}=19.97\right.$, $P<0.001)$. The highest levels of spider mite damage were observed in the treatment with whiteflies, spider mites and A. swirskii. Damage was lower in the treatment with thrips, spider mites and A. swirskii, and the lowest levels of spider mite damage were found when both thrips and whiteflies and A. swirskii were present (Fig. 3).

There was a significant effect of pest species diversity on the densities of predators (Fig. 4) $\left(F_{3,92}=88.45, P<0.001\right)$. The highest predator levels were found in the treatments with thrips, whiteflies and spider mites, where predator levels were at least 11 times higher than in the other treatments at the population peak in week 9 (Fig. 4). Two replicates of the whitefly treatment were slightly contaminated with thrips at the end of the experiment (on average 0.8 larvae leaf $^{-1}$ in week 11), but this was ignored in the statistical analyses.

Not only spider mites, but also whiteflies were controlled significantly better in the presence of thrips (Fig. 5) $\left(F_{1,43}=40.77, P<0.001\right)$, confirming the results of a similar experiment to which no spider mites were added (Messelink et al. 2008). Thrips densities did not differ significantly among treatments $\left(F_{2,66}=0.01, \quad P=0.991\right)$ and were always controlled adequately (Fig. 6), as in experiments reported elsewhere (Messelink et al. 2008).

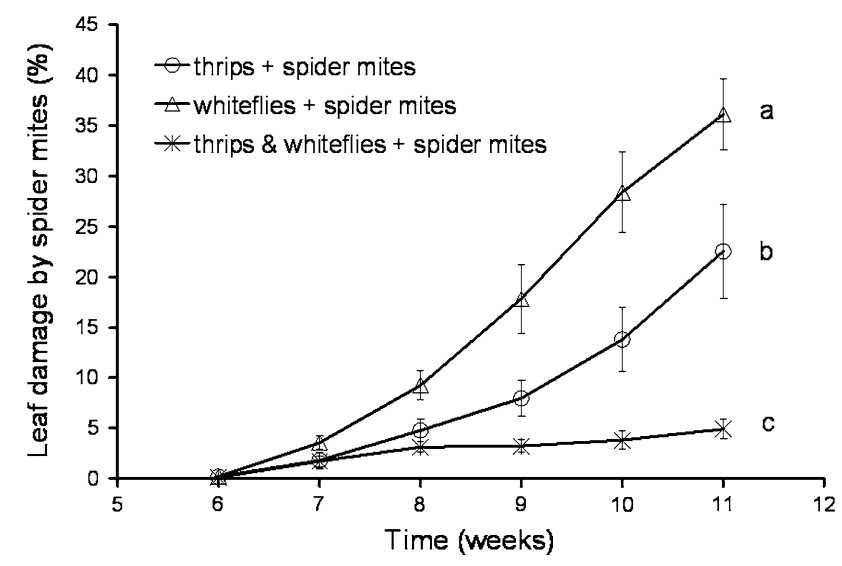

Fig. 3 Leaf damage by two-spotted spider mites in a greenhouse in the presence of the predatory mite A. swirskii and the pest species Western flower thrips, greenhouse whiteflies or Western flower thrips plus greenhouse whiteflies.
Shown are average percentages $( \pm$ SE) of leaf damage on eight marked leaves that neighboured the leaves where spider mites were released. Different letters indicate significant differences among treatments through time (Fisher's LSD test, $P<0.05$ )

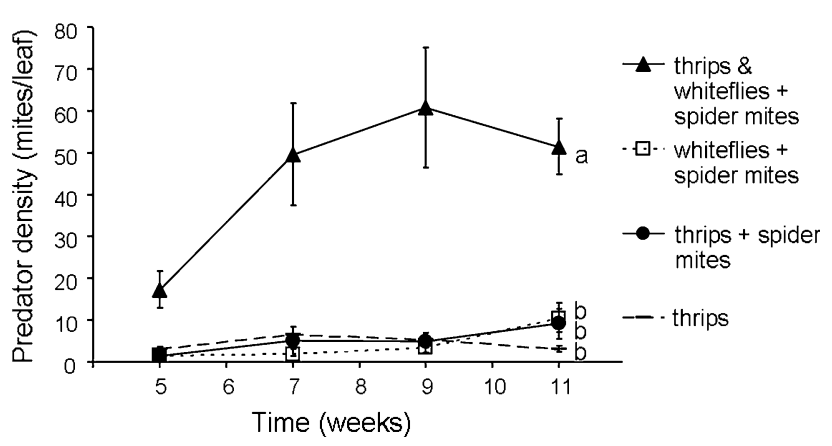

Fig. 4 The dynamics of predatory mites on cucumber plants during an 11-week greenhouse experiment. Shown are average densities $( \pm \mathrm{SE})$ of the predatory mite $A$. swirskii on plants with only Western flower thrips, Western flower thrips plus twospotted spider mites, greenhouse whiteflies plus two-spotted spider mites, and Western flower thrips plus greenhouse whiteflies plus two-spotted spider mites. Different letters indicate significant differences among treatments through time (Fisher's LSD test, $P<0.05$ ) 


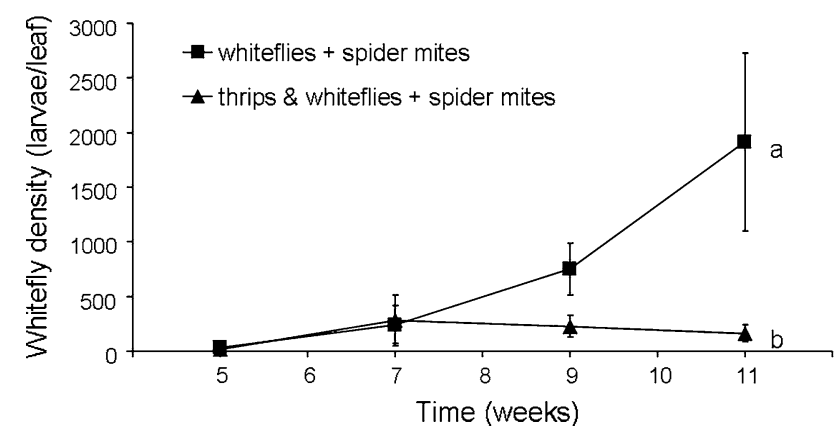

Fig. 5 Greenhouse whitefly densities on cucumber plants in a greenhouse experiment in the presence or absence of Western flower thrips. Plants of both treatments were infested with twospotted spider mites in the fourth week. Shown are average densities $( \pm \mathrm{SE})$ of greenhouse whitefly larvae per leaf. Different letters indicate significant differences among treatments through time (Fisher's LSD test, $P<0.05$ )

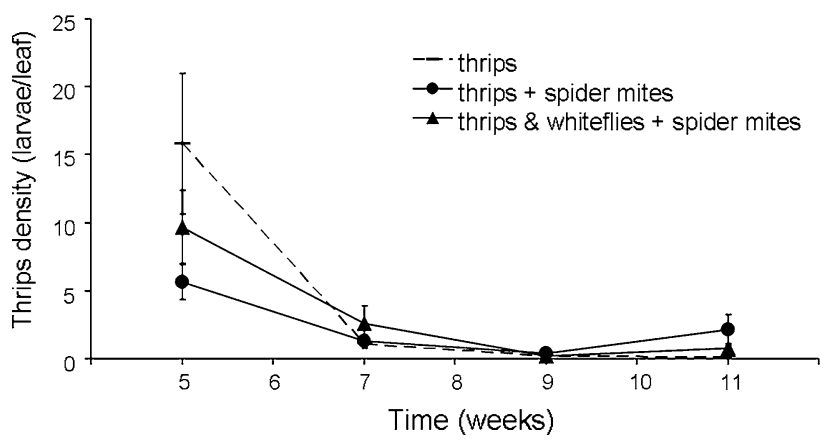

Fig. 6 Densities of Western flower thrips on cucumber plants in a greenhouse experiment in the presence or absence of greenhouse whiteflies and two-spotted spider mites. Shown are

Effects of predator density on spider mite control

The release of predatory mites prior to spider mite infestation significantly affected densities of spider mites (Fig. 7) $\left(F_{2,20}=32.77, \quad P<0.001\right)$. The establishment of spider mites was even prevented on some plants on which high densities of predatory mites were released. The average predatory mite densities in the treatments with low and high predator releases were 7.3 and 11.1 mites leaf $^{-1}$ respectively.

\section{Discussion}

We tested the hypothesis that higher diversity of pest species enhances biological control with generalist predators. Indeed, in the presence of the generalist predatory mite $A$. swirskii, spider mite leaf damage was significantly lower in the presence of both thrips average densities $( \pm \mathrm{SE})$ of Western flower thrips larvae. Differences among treatments were not statistically significant (Fisher's LSD test, $P<0.05$ )

and whiteflies than when there were either thrips only or whiteflies only. Spider mite leaf damage was reduced more in the presence of predatory mites plus thrips than with predatory mites plus whiteflies. In the absence of other pest species or other alternative food such as pollen, A. swirskii was clearly not able to control spider mites and there was hardly any growth of the predator populations.

The exact mechanisms responsible for this strong reduction in spider mite leaf damage in the presence of other pest species cannot be inferred from our experiment; a combination of direct and indirect interactions among the pests can be involved. Direct effects of whiteflies on spider mites are not likely to occur (e.g. reciprocal predation has never been observed), but competition for resources among whiteflies and spider mites might have reduced the growth of spider mite populations. However, because of the high availability of undamaged cucumber leaf 


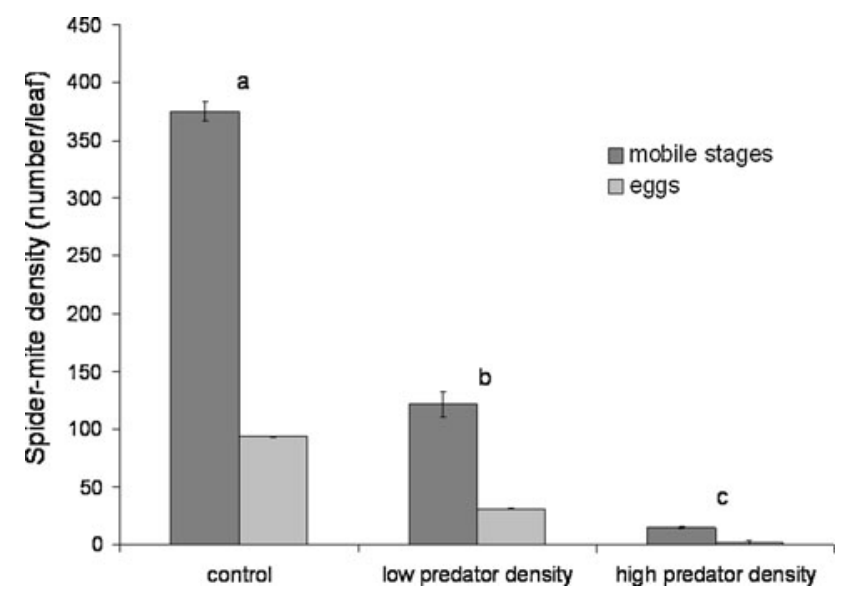

Fig. 7 Two-spotted spider mite densities on cucumber plants on which no, low or high densities of the predatory mite $A$. swirskii were released prior to spider mite infestation. Shown are average densities $( \pm \mathrm{SE})$ of mobile stages and eggs of

tissue, we assume this to be of minor importance. If resource competition did strongly affect the population growth of spider mites, we would expect higher levels of spider mite leaf damage in the treatment with lower whitefly levels. However, the opposite occurred: lower levels of spider mite leaf damage were found at lower levels of whiteflies. This suggests that some other mechanism suppressed spider mites, such as indirect interactions of whiteflies with spider mites via the plant or via the predator. Unlike whiteflies, thrips do not only act as herbivores, but also as predators of spider mite eggs (intraguild predation, Trichilo and Leigh 1986). These direct effects on spider mites might explain the lower densities of spider mites in the presence of thrips than in the presence of whiteflies. As predator densities did not differ significantly between these two treatments (Fig. 4), it is less likely that predator densities are responsible for the strong difference in effects on spider mites. Competition for food between the spider mites and the thrips is also not likely to have occurred, because thrips levels were quite low $\left(<5\right.$ larvae leaf $\left.^{-1}\right)$. However, other studies have shown that thrips hide inside the webbing produced by spider mites when predators are present (Pallini et al. 1998; Venzon et al. 2000), so that local competition between thrips and spider mites might have played a role. Nevertheless, it is likely that the lower levels of spider mite leaf damage were a result of predatory mites as well as thrips feeding on spider mites. The hiding of thrips in the spider mite webbing spider mites per leaf, two weeks after the plants were infested with 20 females of spider mites per leaf. Different letters indicate significant differences among treatments for the sum of egg and mobile stages (Fisher's LSD test, $P<0.05$ )

could also result in reduced control of thrips (Magalhães et al. 2007), but we found no evidence for this, possibly because the amount of spider mite webbing was too low.

Whiteflies and thrips might have reduced population growth rates of spider mites indirectly via the plant, as attacks of plants by one pest species can induce resistance mechanisms in the plant, which can subsequently slow the population growth of a second pest species (Karban and Carey 1984). This so-called induced resistance has potential for improving biological control (Karban et al. 1997). Further experiments are needed to clarify if such induced resistance occurs among the pest species in this study. Induced resistance might even have affected the consumption of spider mite eggs by thrips. On cotton, it was shown that induced plant resistance caused thrips to shift more towards predation than herbivory (Agrawal et al. 1999), but the reduced density and quality of spider mites on induced plants may antagonize this shift towards increased predation (Agrawal and Klein 2000).

The second indirect interaction between the pests that possibly resulted in lower levels of spider mite leaf damage is mediated by the shared predator. Our laboratory experiment shows that, despite the predators experiencing hinder from the spider mite webbing, predation of spider mite eggs still occurred. We decided to use spider mite eggs because they cannot escape from the web, but in the greenhouse, all stages of spider mites were present. We assume that the 
effects of the predators on spider mites in the greenhouse were mainly based on consumption of mobile stages outside or near the edges of spider mite webbing.

Reduction of spider mite leaf damage in the presence of other pests may well arise as a consequence of the strong numerical response of the predator when a second or third pest species was present in addition to the spider mites. Indeed, predator densities were higher when thrips and whiteflies were present together with spider mites, with up to 50 times higher densities when both thrips and whiteflies were added. The experiment where two densities of predatory mites were released prior to spider mite infestations clearly shows that higher predator densities reduce spider mite densities more than lower predator densities. So besides all other possible direct and indirect pest interactions, we suggest that predator densities are to a large extent responsible for the improved suppression of spider mites in the presence of other pest species. Not only spider mites, but also whiteflies were better controlled at higher predator densities due to the presence of both thrips and whiteflies. These predator-mediated interactions among the three pest species can be classified as apparent competition, with the addition of thrips to a system of spider mites and whiteflies resulting in lower levels of spider mite leaf damage and better control of whiteflies.

In addition to these density effects, several traitmediated effects might have occurred as well. These occur when one species modifies the interaction between a pair of species by changing the behaviour of individuals of one or more of these species (not their numbers) (Prasad and Snyder 2006). We suggest that thrips larvae inside spider mite webbing may have caused spider mites to move out of the webbing, thereby making them more susceptible to predation.

Our results suggest that generalist phytoseiid mites such as A. swirskii can play an important role in reducing the colonization of a crop by spider mites, even when they are incapable of controlling spider mites alone. To which extent $A$. swirskii can control starting colonies of spider mites depends, at least partly, on the predator densities at the time of infestation, and thus of the presence of food for sustaining predator populations. The sequence of crop infestation by different pest species is therefore very important for the control of spider mites by
A. swirskii, at least in crops where alternative food sources such as pollen are not available. Once spider mites have formed colonies, generalist predators such as A. swirskii cannot control them, and more specialized spider mite predators, such as $P$. persimilis, will be needed for spider mite control.

The higher predator densities in the treatments with more than one pest species may not have been merely caused by increased prey availability alone. Previous experiments showed that juveniles of A. swirskii survive and develop better on a mixed diet of thrips and whiteflies than on a single diet of either of these species. These effects of a mixed diet were suggested to be responsible for strong increases in predator densities in greenhouses in which both thrips and whiteflies were present, and consequently, for lower densities of whiteflies in the presence of thrips (Messelink et al. 2008). The high predator densities observed in the treatment with thrips, whiteflies and spider mites together support this idea. In theory, the addition of spider mites to a menu of thrips or whiteflies could have had the same effect, but the present results show no evidence for this: the addition of spider mites to treatments with thrips did not result in an increased predator population compared to a treatment with only thrips. Maybe spider mite densities were too low for such an effect to occur. We suggest that both the higher availability of prey and the effects of a mixed diet contributed to a high predator population. These high predator densities, in turn, contributed to improved control of spider mites. Although A. swirskii is not an efficient spider mite predator, it nevertheless reduced spider mite damage when the predator-prey ratio was sufficiently high.

In summary, we provide evidence that diversity of pest species enhances biological control of whiteflies and spider mites with a generalist predatory mite. Similar effects might also be achieved by adding a non-pest alternative food source, such as pollen. Several studies have shown the benefit of pollen in terms of enhancing pest control (Nomikou et al. 2002, 2009; van Rijn et al. 2002), but so far, this has not resulted in large-scale applications. Our results furthermore suggest that it might be advantageous to allow or create some pest species diversity in a crop, rather than to try to exterminate all phytophages present. Further experiments have to be done to determine whether the total crop damage of three or 
two pest species is less than the damage inflicted by one of the pest species. Releasing pest species in a crop is considered risky, but is accepted in some cases, such as in sweet pepper, where some growers use the "pest-in-first" strategy with spider mites to enhance control by P. persimilis (Hussey et al. 1965; K. Bolckmans, R\&D Department, Koppert BV, personal communication). Avoiding total eradication of all pest species, thereby maintaining some pest diversity, might be more acceptable for the growers than introducing a new pest. For example, for cotton it has been suggested to leave a "pest residue" as food for predators early in the season in order to enhance biological control of pests that occur later in the season (Luckmann and Metcalf 1975; Gonzalez and Wilson 1982). The demonstrated effects of pest diversity on a generalist predator in this study might furthermore be useful for evaluation programs of "new" generalist predators by assessing their performance not only on the target prey alone, but also in the presence of other relevant pest species.

Acknowledgments This study was supported by the Dutch Ministry of Agriculture, Nature and Food Quality. RvM received a $\mathrm{PhD}$ scholarship from the Technology Foundation (STW project 7180 ). E. de Groot and W. van Wensveen are thanked for their assistance in the greenhouse experiments.

Open Access This article is distributed under the terms of the Creative Commons Attribution Noncommercial License which permits any noncommercial use, distribution, and reproduction in any medium, provided the original author(s) and source are credited.

\section{References}

Abrams PA, Matsuda H (1996) Positive indirect effects between prey species that share predators. Ecology 77:610-616

Abrams PA, Holt RD, Roth JD (1998) Apparent competition or apparent mutualism? Shared predation when populations cycle. Ecology 79:201-212

Agrawal AA, Klein CN (2000) What omnivores eat: direct effects of induced plant resistance on herbivores and indirect consequences for diet selection by omnivores. J Anim Ecol 69:525-535

Agrawal AA, Kobayashi C, Thaler JS (1999) Influence of prey availability and induced host-plant resistance on omnivory by western flower thrips. Ecology 80:518-523

Cardinale BJ, Harvey CT, Gross K, Ives AR (2003) Biodiversity and biocontrol: emergent impacts of a multienemy assemblage on pest suppression and crop yield in an agroecosystem. Ecol Lett 6:857-865
Casula P, Wilby A, Thomas MB (2006) Understanding biodiversity effects on prey in multi-enemy systems. Ecol Lett 9:995-1004

Collyer E (1964) The effect of an alternative food supply on the relationship between two Typhlodromus species and Panonychus ulmi (Koch) (Acarina). Entomol Exp Appl 7:120-124

Denoth M, Frid L, Myers JH (2002) Multiple agents in biological control: improving the odds? Biol Control 24:2030

Evans EW, Stevenson AT, Richards RD (1999) Essential versus alternative foods of insect predators: benefits of a mixed diet. Oecologia 121:107-112

Gonzalez D, Wilson LT (1982) A food-web approach to economic thresholds: a sequence of pests/predaceous arthropods on California cotton. Entomophaga 27:31-43

Harmon JP, Andow DA (2004) Indirect effects between shared prey: predictions for biological control. BioControl 49:605-626

Holt RD (1977) Predation, apparent competition and the structure of predator-prey communities. Theor Popul Biol 12:197-229

Holt RD, Kotler BP (1987) Short-term apparent competition. Am Nat 130:412-430

Holt RD, Lawton JH (1994) The ecological consequences of shared natural enemies. Annu Rev Ecol Syst 25:495-520

Hussey NW, Parr WJ, Gould HJ (1965) Observations on the control of Tetranychus urticae Koch on cucumbers by the predatory mite Phytoseiulus riegeli Dosse. Entomol Exp Appl 8:271-281

Janssen A, Pallini A, Venzon M, Sabelis WM (1998) Behaviour and indirect food web interactions among plant inhabiting arthropods. A review. Exp Appl Acarol 22:497-521

Janssen A, Montserrat M, HilleRisLambers R, de Roos AM, Sabelis MW (2006) Intraguild predation usually does not disrupt biological control. In: Brodeur J, Boivin G (eds) Trophic and guild interactions in biological control. Springer, Dordrecht, pp 21-44

Janssen A, Sabelis MW, Magalhães S, Montserrat M, van der Hammen T (2007) Habitat structure affects intraguild predation. Ecology 88:2713-2719

Karban R, Carey JR (1984) Induced resistance of cotton seedlings to mites. Science 225:53-54

Karban R, Hougen-Eitzman D, English-Loeb GM (1994) Predator-mediated apparent competition between two herbivores that feed on grapevines. Oecologia 97:508-511

Karban R, English-Loeb G, Hougen-Eitzman D (1997) Mite vaccinations for sustainable management of spider mites in vineyards. Ecol Appl 7:183-193

Koss AM, Snyder WE (2005) Alternative prey disrupt biocontrol by a guild of generalist predators. Biol Control 32:243-251

Liu CZ, Yan L, Li HR, Wang G (2006) Effects of predatormediated apparent competition on the population dynamics of Tetranychus urticae on apples. BioControl 51:453-463

Luckmann WH, Metcalf RL (1975) The pest-management concept. In: Metcalf RL, Luckmann WH (eds) Introduction to insect pest management. John Wiley, New York, pp 3-35 
Magalhães S, van Rijn PCJ, Montserrat M, Pallini A, Sabelis MW (2007) Population dynamics of thrips prey and their mite predators in a refuge. Oecologia 150:557-568

Messelink GJ, van Steenpaal SEF, Ramakers PMJ (2006) Evaluation of phytoseiid predators for control of Western flower thrips on greenhouse cucumber. BioControl 51:753-768

Messelink GJ, van Maanen R, van Steenpaal SEF, Janssen A (2008) Biological control of thrips and whiteflies by a shared predator: two pests are better than one. Biol Control 44:372-379

Momen FM, El-Saway SA (1993) Biology and feeding behaviour of the predatory mite, Amblyseius swirskii (Acari: Phytoseiidae). Acarologia 34:199-204

Nomikou M, Janssen A, Schraag R, Sabelis MW (2001) Phytoseiid predators as potential biological control agents for Bemisia tabaci. Exp Appl Acarol 25:271-291

Nomikou M, Janssen A, Schraag R, Sabelis MW (2002) Phytoseiid predators suppress populations of Bemisia tabaci on cucumber plants with alternative food. Exp Appl Acarol 27:57-68

Nomikou M, Sabelis MW, Janssen A (2009) Pollen subsidies promote whitefly control through the numerical response of predatory mites. BioControl (in press). doi: 10.1007/s10526-009-9233-x

Overmeer WPJ (1985) Rearing and handling. In: Helle W, Sabelis MW (eds) Spider mites: their biology, natural enemies and control, vol 1B. Elsevier, Amsterdam, pp $161-170$

Pallini A, Janssen A, Sabelis MW (1998) Predators induce interspecific herbivore competition for food in refuge space. Ecol Lett 1:171-177

Park YL, Lee JH (2002) Leaf cell and tissue damage of cucumber caused by twospotted spider mite (Acari: Tetranychidae). J Econ Entomol 95:952-957

Prasad RP, Snyder WE (2006) Diverse trait-mediated interactions in a multi-predator, multi-prey community. Ecology 87:1131-1137
Rosenheim JA, Kaya HK, Ehler LE, Marois JJ, Jaffee BA (1995) Intraguild predation among biological control agents: theory and evidence. Biol Control 5:303-335

Sabelis MW, Bakker FM (1992) How predatory mites cope with the web of their tetranychid prey: a functional view on dorsal chaetotaxy in the Phytoseiidae. Exp Appl Acarol $16: 203-225$

Symondson WOC, Cesarini S, Dodd PW, Harper GL, Bruford MW, Glen DM, Wiltshirem CW, Harwood JD (2006) Biodiversity vs. biocontrol: positive and negative effects of alternative prey on control of slugs by carabid beetles. Bull Entomol Res 96:637-645

Toft S (1995) Value of the aphid Rhopalosiphum padi as food for cereal spiders. J Appl Ecol 32:552-560

Tomerlin JR, Howell TA (1988) DISTRAIN: a computer program for training people to estimate disease severity on cereal leaves. Plant Dis 72:455-459

Trichilo PJ, Leigh TF (1986) Predation on spider mite eggs by the Western Flower Thrips, Frankliniella occidentalis (Thysanoptera: Thripidae), an opportunist in a cotton agroecosystem. Environ Entomol 15:821-825

van Rijn PCJ, van Houten YM, Sabelis MW (2002) How plants benefit from providing food to predators even when it is also edible to herbivores. Ecology 83:2664-2679

van Veen FJF, Memmott J, Godfray HCJ (2006) Indirect effects, apparent competition and biological control. In: Brodeur J, Boivin G (eds) Trophic and guild interactions in biological control. Springer, Dordrecht, pp 145-169

Venzon M, Janssen A, Pallini A, Sabelis MW (2000) Diet of a polyphagous predator affects refuge-seeking of its prey. Anim Behav 60:369-375

Wallin H, Chiverton PA, Ekbom BS, Borg A (1992) Diet, fecundity and egg size in some polyphagous predatory caribid beetles. Entomol Exp Appl 65:129-140

Zannou ID, De Moraes GJ, Ueckermann EA, Oliveira AR, Yaninek S, Hanna R (2007) Phytoseiid mites of the subtribe Amblyseiina (Acari: Phytoseiidae: Amblyseiini) from sub-Saharan Africa. Zootaxa 1550:1-47 